\title{
Improving the accuracy of determining the parameters of induction motors in transient starting modes
}

Oleksiy Iegorov ${ }^{1}$,

Olga Iegorova ${ }^{2}$,

Oleksandr Miroshnyk²,

Oleksandr Savchenko

${ }^{1}$ O. M. Beketov National University

of Urban Economy in Kharkiv,

17 Marshal Bazhanov St.,

61002 Kharkiv, Ukraine

Email:diaskk67@gmail.com

${ }^{2}$ Kharkiv Petro Vasylenko National

Technical University of Agriculture,

44 Alchevskih St.,

61052 Kharkiv, Ukraine
Nowadays, it becomes important to solve the problem of improving mathematical models of AC electric machines in order to clarify the analytical description of transients taking into account the active resistance in the stator winding. The use of frequency characteristics will improve the accuracy of determining the design parameters of induction motors at the design stage. In this case, taking into account the active resistance of the stator winding makes it possible to determine with sufficient accuracy the characteristics of the engine in the starting modes.

Keywords: induction motor, frequency characteristics, winding resistance, starting mode of operation, attenuation coefficient

\section{INTRODUCTION}

When designing induction motors, it is necessary to ensure that their characteristics meet the requirements of the technical specifications and current standards. For this, it is necessary to achieve a coincidence of the calculated and experimental data. According to existing methods for calculating induction motors, the parameters are not calculated accurately enough. The groove scattering and the saturation coefficient are calculated by the equivalent slot opening, which is calculated by empirical formulas. The inductive differential scattering resistance is also calculated by the empirical formula, which does not always give a reliable result.
Accuracy analysis requirements for transients occurring in electrical machines (EM) and electrical energy power systems in normal and emergency modes are continuously increasing. An in-depth study of the behaviour of EM in dynamic modes is one of the most important factors determining the electrical machines rational design, as well as the energy power systems, power supply circuits, control systems and process control systems design and operation in all industries areas.

Reliable predestination for the EM behaviour in transient modes depends on the mathematical models accuracy adopted for the study and the information completeness reflecting their physical dynamic properties. This necessitates the improvement for existing EM models in the direction 
on increasing their physical validity, as well as the creation for algorithms of modelling transient processes that provide quick and visual results with a given accuracy in solving practical problems.

When using traditional methods for calculating transients, taking into account various conditions in these processes leads to significant difficulties calculation due to the increase in the differential equations order that describes transients.

Frequency methods have become widespread in engineering practice for studying the EM dynamic modes. They have great simplicity and clarity, and also allow you to directly use for the calculation of experimental data in the form of frequency characteristics for individual elements or the entire system as a whole.

Modern methods of analysis allow us to consider transients taking into account many electrical circuits on the rotor using frequency methods based on the properties from the Fourier integral and the Laplace transform. In [1,2], it is proposed to use the discrete Fourier transform on the basis of experimental data to determine the frequency characteristics and obtain a mathematical EM model in the frequency domain. However, with this approach, there are limitations on both time and frequency. When processing research results, one has to deal with the uncertainty principle for the signal processing domain. The principle here is called the Benedict Theorems: a function cannot be simultaneously limited in the time range and in the frequency range.

Currently, thanks to the use of high-performance computing, an opportunity has appeared to apply frequency research methods. Results of these studies have great simplicity and clarity, and also allow you to directly use experimental data for calculation in the form of frequency characteristics of individual elements or the entire system.

Frequency characteristics are understood to mean the dependence of the stator current complex values (conductivity on the stator winding side) on the rotor speed in steady-state conditions when the stator is supplied with a nominal voltage and nominal frequency.

Accounting for changes in the rotational speed of the rotor of an induction motor is possible using frequency research methods. The initial data for the calculation are the following:
- Conductivity frequency response of an induction motor $y(j s)=\frac{1}{x(j s)}$ [4] (Fig. 1);

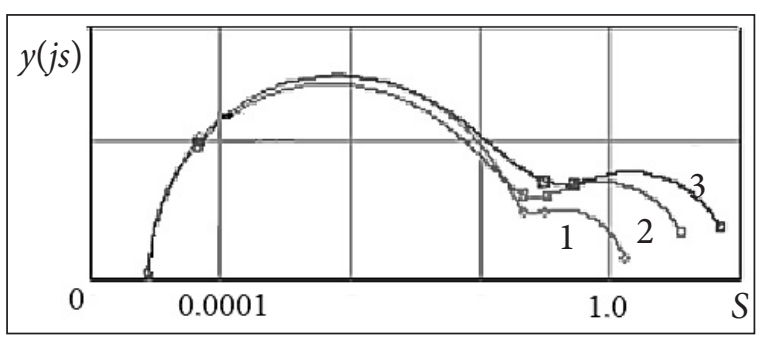

Fig. 1. The frequency characteristics of conductivity depending on voltage: $U=0.25 U n(1), U=0.5 U n(2), U=0.7 \cup n$ (3)

- Angle $\gamma_{0}$ between the axis of the fixed winding of phase $A$ of the stator and the voltage vector at the time of switching on;

- Stator winding resistance to the direct current $r_{s}$;

- Slip $s$ at the moment the engine is switched on.

When the motor is connected to the network, the following current components will flow in the stator winding: steady-state current $i_{s 0}$, aperiodic $i_{s 1}$ and transient periodic $i_{s 2}$.

The use of the method of spatial complexes in combination with frequency methods allows for refined studies based on the analytical description of transients. At the same time, such phenomena as electromagnetic rotor balance, current displacement in windings, the presence of circuit's unlimited number in electrical machines, as well as the saturation effect for the magnetic flux paths of electromagnetic modules can be taken into account.

Further improvement of methods for calculating electromechanical transients in electric machines is based on factors such as the powerful computing equipment global distribution, the creation of performance characteristics reliable databases for synchronous and asynchronous electric machines, and the development of methods for analysing and synthesizing equivalent circuitry that adequately describe the initial options.

The aim of research is to solve the problem of improving the mathematical models of alternating current EMs, in order to clarify the analytical description of transients taking into account the active resistance in the stator winding. 
The theoretical background for the study processes transient in EM is based on the relationships established in [3] between transient processes in EM and frequency characteristics. In [6-8] it is shown that the flow of a transient process during a short circuit, or switching on the EM in the network, disconnecting it from the network, changes in the supply voltage, etc., what corresponds to a set of steady-state modes when the stator is supplied with a nominal AC voltage and nominal frequency but at different rotor slips.

With its great simplicity and clarity, the method allows us to obtain an analytical solution for the refined study of electromagnetic transients in $\mathrm{EM}$ at a quasi-constant rotor rotation frequency in the separate time intervals transient process.

\section{METHODOLOGY}

The active resistance in the stator winding circuit influence affects not only the change in the decay time constants on the transient current components, but also the change in their amplitudes and phases at the operation mode change initial moment.

When taking into account the winding active resistance $r_{s}$ influence, the current components vectors, when switching on the EM in the network, can be determined in accordance with recommendations [3] on the conductivity $y_{r}(j s)$ frequency response, calculated taking into account the stator active resistance influence, in the same way as characteristic of $y(j s)$ which excludes this resistance.

In this case, the transient current calculation in the stator winding when the EM is turned on the network, rotating with a constant slip, is performed in the following sequence.

The dependence of the conductivity on the slip of the rotor is calculated taking into account the influence of the stator winding resistance $y_{r}(j s)$

$$
y_{r}(j s)=\frac{j}{r_{S}+j x(j s)},
$$

where $x(j s)=\frac{1}{\frac{1}{x_{\sigma}+x_{\mu}}+\sum_{k=1}^{n} \frac{j s}{j s+r_{k}}}$ is determined by the parameters of the equivalent L-shaped equivalent circuit (Fig. 2); s is slip.

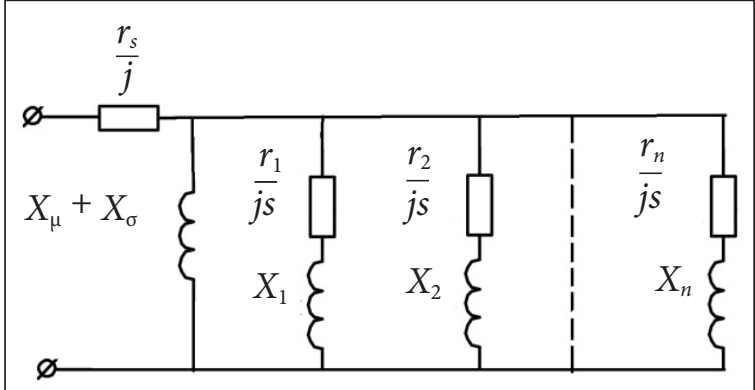

Fig. 2. The equivalent L-shaped circuit

The stator steady-state current vector is calculated from the characteristic $y_{r}(j s)$ for a given slip $s$, at the switching on the moment:

$$
i_{s r 0(t=0)}=y_{\mathrm{r}}(j s) .
$$

The stator steady-state current change in time has the form:

$$
i_{s r 0}(t)=i_{s r 0(t=0)} j j^{\omega} t
$$

The transient current aperiodic component $i_{s r 0(t=0)}$ at time $t=0$ is determined by the point on the characteristic $y_{r}(j s)$ during the slip (1-s).

The aperiodic current change in time is subject to the following law:

$$
i_{s r 1}(t)=i_{s r 0(t=0)} e^{1 \omega \omega_{a} t} \cdot e^{\frac{-t}{T_{a}}} .
$$

The rotation natural frequency and the decay time electromagnetic constant of the electrical current aperiodic component are determined using the frequency response $y_{r}(j s)$.

The initial value for the full periodic current vector $i_{s r 2(t=0)}$ is calculated from the condition $i_{s r(t=0)}+i_{s r 1(t=0)}+i_{s r 2(t=0)}=0$.

Consequently,

$$
i_{s r 2(t=0)}=i_{s r 0(t=0)}-i_{s r 1(t=0) .}
$$

The change law for the periodic current decay over time, taking into account the active resistance influence in the stator winding, will be as follows:

$$
i_{s r 2}(t)=\left(\sum_{k=1}^{N} i_{s r 2 k} e^{\frac{-t}{T_{a}}}\right) e^{j(1-s) t}
$$

Here $i_{s 2 k}$ and $T_{r k}$ are the initial values and time constants for the periodic current components 
attenuation, taking into account the stator winding active resistance influence.

The initial values of the current components $i_{s r 2 k}$ and $i_{s r 2}$ in [3] are determined with the help of complexes that do not take into account the influence of $r_{s}$ by multiplying them by a special correction coefficient, which is equal to the ratio of the complex conductivity obtained taking into account the active resistance $r_{s}$ to the complex conductivity received without considering this active resistance $r_{s}$

$$
i_{s r 2 k}=i_{s 2 k} \frac{i_{s r 2(t=0)}}{i_{s 2(t=0)}},
$$

where $i_{s 2 k}$ components are calculated by the expression

$$
i_{s 2 k}=\frac{r_{k}}{\left(j r_{k}+(1-s) x_{k}\right)\left(r_{k}+j s x_{k}\right)},
$$

excluding active resistance in the winding $i_{s 2(t=0)}=\sum_{k=1}^{N} i_{s 2 k}$.

It is possible to determine the transient periodic current components directly from the equivalent circuit parameters. When taking into account the active resistance influence, the stator winding active resistance

$$
i_{s 2 r k}=y_{r k}(j s)=\frac{1}{r_{k}+j s x_{k}} \cdot \frac{1}{x_{v}(j s)},
$$

where $x_{v}(j s)=\frac{r_{s}}{j}\left(\frac{j}{r_{s}}+\frac{1}{x_{\mathrm{o}}+x_{\mathrm{i}}}+\sum_{k=1}^{N} \frac{j s}{j s x_{k}+r_{k}}\right)$.

Consequently,

$$
i_{s r k 2}(t=0)=y_{r k}^{(j s)}{ }_{s=s-1}-y_{r k}^{(j s)}{ }_{s=s} \text {. }
$$

To reduce the computer time cost, you can use the approximate calculation for the attenuation coefficients and the corresponding time constants of aperiodic currents in rotor circuits using the ratios obtained in [3]

$$
\begin{aligned}
& \alpha_{r k}=\frac{r_{k}}{x_{k}}\left(1+r_{k} \frac{\frac{r_{k}}{x_{k}^{2}}}{(1-s)^{2}+\left(\frac{r_{k}}{x_{k}}\right)^{2}}\right), \\
& T_{r k}=\frac{1}{\alpha_{r k}},
\end{aligned}
$$

where $r_{k}, x_{k}$ are the parameters of an equivalent L-shaped equivalent circuit, adequate to the frequency response $y(j s)$ without taking into account the stator winding active resistance.

Thus, taking into account the influence from active resistance in the stator winding circuit, the change law in the stator transient current over time in fixed axes, provided that the slip is constant, will have the following form:

$$
\begin{aligned}
& i_{s r}(t)=i_{s r 0(t=0)} e^{j \omega t}+i_{s r 1(t=0)} e^{j \omega \omega_{c} t} e^{-\frac{t}{T_{a}}}+ \\
& \sum_{k=1}^{N} i_{s r k 2} e^{j(1-s) \omega t} e^{-\frac{t}{T_{a}}} .
\end{aligned}
$$

If there is a large active resistance $r_{s}$ in the motor stator circuit, it is necessary to introduce the following corrections to take into account its influence.

Frequency characteristics should be used, adjusted for the effect of active resistance influence:

$$
\begin{aligned}
& y_{d r}(j s)=\frac{j}{r_{s}+j x_{d}(j s)}, \\
& y_{q r}(j s)=\frac{j}{r_{s}+j x_{q}(j s)} .
\end{aligned}
$$

The current aperiodic component average value $i_{\text {slav }}$ is also determined taking into account the active resistance $r_{s}$ for the slip value $s=-(1-s)$.

The component initial value having a frequency close to double and due to the magnetic and electrical asymmetry in the rotor, $D i_{s 0}$ is determined as in the case of the active resistance absence in the stator winding circuit based on the frequency characteristics:

$$
\begin{aligned}
& y_{d}(j s)=\frac{j}{j x_{d}(j s)}, \\
& y_{q}(j s)=\frac{j}{j x_{q}(j s)} .
\end{aligned}
$$

Exact accounting for the active resistance influence $r_{s}$ on the damping factor $a_{a}$ and the aperiodic component $i_{s 1}$ rotation frequency $w_{\mathrm{a}}$ is difficult and can be done by finding the characteristic equation [8]:

$$
\begin{aligned}
& D(p)=\left(r_{s}+x_{d}(p)\right)\left(r_{s}+x_{q}(p)\right)++ \\
& x_{d}(p) x_{q}(p)(1-s) .
\end{aligned}
$$


The periodic transition current $i_{s 2}$ initial value is determined as in the case for the active resistance absence from the condition:

$$
\left(i_{s 0}+i_{s 1}+i_{s 2}\right)_{t=0}=0
$$

Refinement from the effect on the $i_{s 2 k}$ current components decay time constants is performed either by finding the equation roots (12) or by relations from the form (10):

$$
\begin{aligned}
& \alpha_{r d(q) k}=\frac{r_{r d(q) k}}{x_{r d(q) k}}\left(1+r_{s} \frac{\frac{r_{r d(q) k}}{x_{r d(q) k}^{2}}}{(1-s)^{2}+\left(\frac{r_{r d(q) k}}{x_{r d(q) k}}\right)^{2}},\right. \\
& T_{r d(q) k}=\frac{1}{\alpha_{r d(q) k}} .
\end{aligned}
$$

As shown in [8], in the rotor asymmetry presences, the characteristic equation roots (13), which characterize the attenuation coefficients for the current components is 2 , have no imaginary parts. This means that all components have the same frequency and rotate with frequency $(1-S)$ in the fixed stator coordinates.

\section{VERIFICATION OF THE THEORETICAL FINDINGS}

In the study, an induction motor with a power on $130 \mathrm{~kW}$ and a number of 4 poles was analysed in the starting modes taking into account the stator active resistance.

In Figs. 3 and 4, the time dependences for the moment and currents in phases in the induction motor starting transient mode are presented.

Analysis of the results of calculations and experimental studies showed a good convergence. The maximum discrepancy was not more than $9.6 \%$. This fact gives a reason to talk about the possibility of using this method in determining the starting characteristics of an induction motor during its design.

In the starting mode of the induction motor, there is a very strong saturation of the magnetic circuit and saturated values of inductive resistances. The distribution curve of the induction over the entire circumference was expanded in a Fourier series. When calculating the field in the air gap, no higher harmonics currents are introduced into the rotor slots. This is equivalent to the fact that the rotor branches of these harmonics are open.

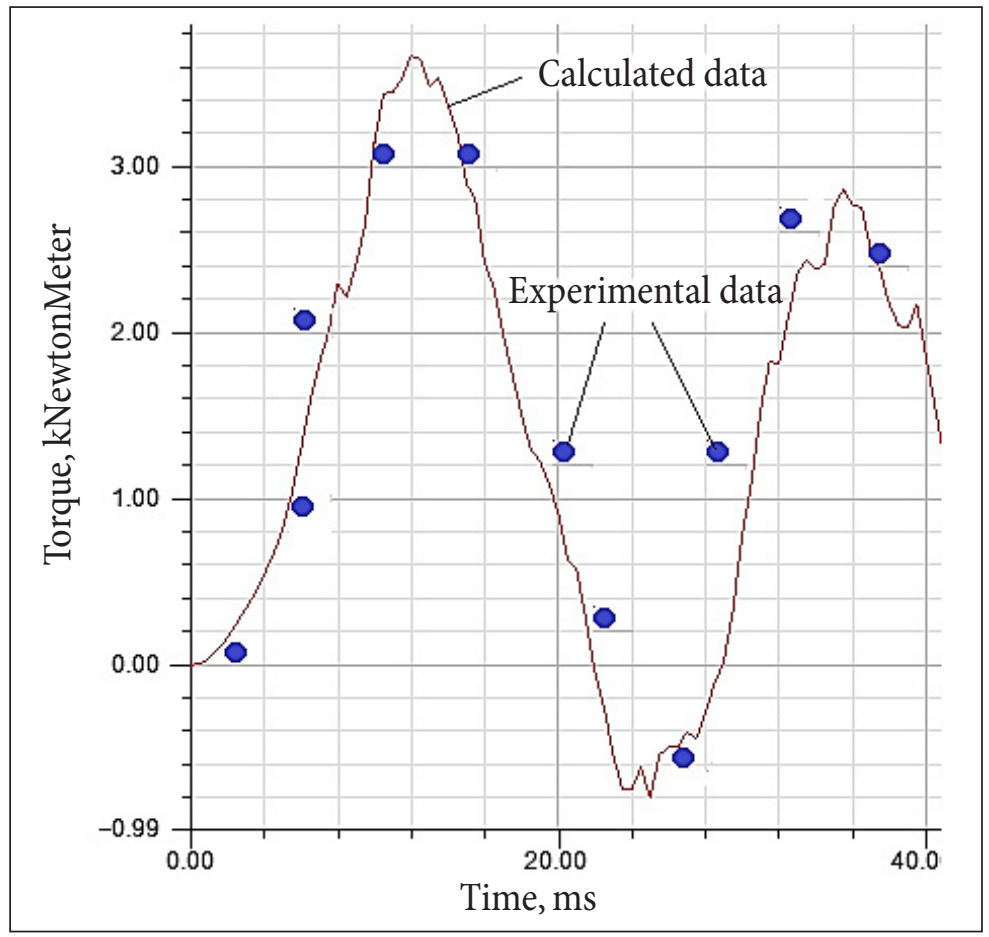

Fig. 3. The motor shaft torque characteristic obtained by experimental and calculation methods 


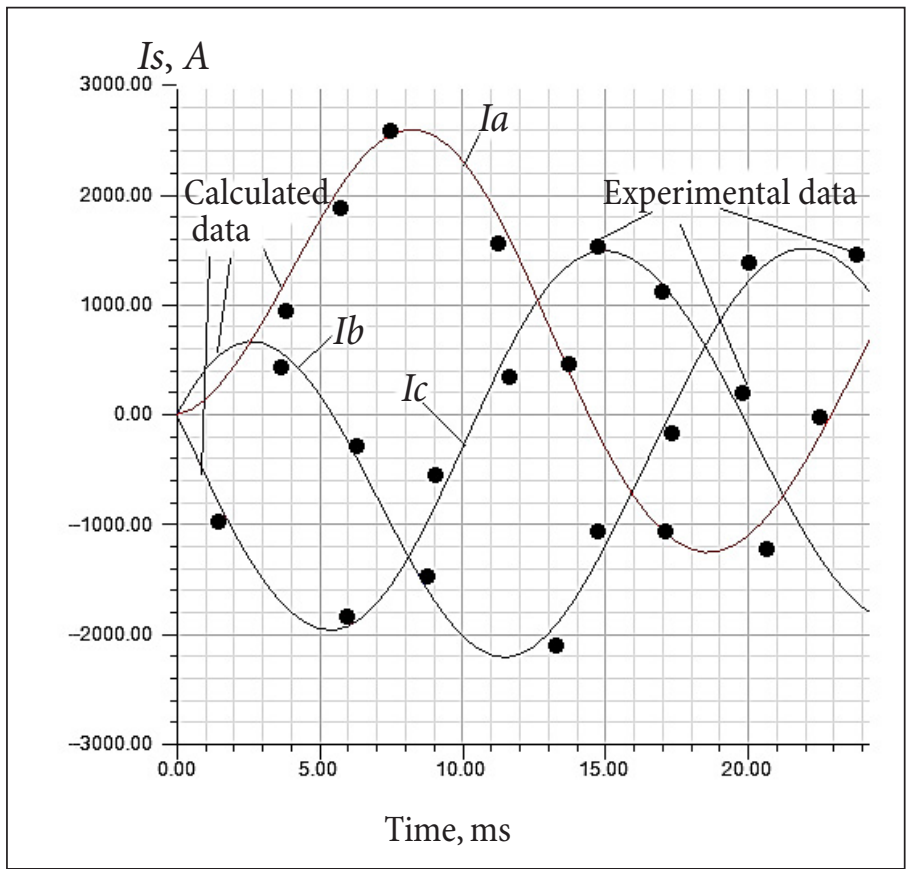

Fig. 4. Stator currents characteristic obtained by experimental and calculation methods

This leads to a distortion of the results of electromagnetic calculations.

Next, the effect of current displacement in the rotor on the characteristics of an induction motor is considered. The dependences reflecting the quadratic dependence of the increase in rotor resistance at higher harmonics are given in $[10,11]$. Taking into account that when analysing the starting characteristics, the frequency in the rotor varies up to $50 \mathrm{~Hz}$, with a sufficient degree of accuracy we can take into account the effect of the current displacement effect by the linear dependence

$$
R_{2 s}=R_{2}(1+c \cdot s) \text {, }
$$

where $c$ is the coefficient of increase in the active resistance of the rotor.

The resistance of the rotor chain, taking into account its change from the slip of the rotor $s$, is

$$
Z_{2}(s)=\sqrt{\left(\frac{R_{2}}{s}+c \cdot R_{2}\right)^{2}+x_{2}^{2}} .
$$

The general expression for the rotor current can be represented through the resistance of the equivalent circuit as

$$
\begin{aligned}
& I_{2}(s)=\frac{U_{\text {ном }}}{\sqrt{\left(R_{1}^{2}+x_{1}^{2}\right)} \cdot} \rightarrow \\
& \rightarrow \frac{U_{\text {ном } \times}}{\cdot\left[\sqrt{\left(\frac{1}{s^{2}} R_{2}+\frac{2}{s} c R_{2}^{2}+c^{2} R_{2}^{2}+x_{2}^{2}\right)}+\sqrt{\left(R_{\mathrm{i}}^{2}+x_{\mathrm{i}}^{2}\right)}\right]+} \\
& \rightarrow \frac{\times \sqrt{\left(R_{\mathrm{i}}^{2}+x_{\mathrm{i}}^{2}\right)}}{+\sqrt{\left(R_{\mathrm{i}}^{2}+x_{\mathrm{i}}^{2}\right)\left(\frac{1}{s^{2}} R_{2}+\frac{2}{s} c R_{2}^{2}+c^{2} R_{2}^{2}+x_{2}^{2}\right)}} .
\end{aligned}
$$

It should be noted that for calculations at the design stage, when determining static characteristics, methods have been developed that allow taking into account the effect of current displacement and saturation of the magnetic circuit. These techniques provide acceptable accuracy, depending on the shape of the groove of the rotor, but they are not applicable in the calculation of dynamic characteristics. The modern development of computer technology, in particular, the emergence of such a powerful software product as Ansys Maxwell, sets the task of using the opportunities that have appeared to increase the accuracy of calculations.

Ansys Maxwell is a powerful interactive environment for modelling and calculations of most 
scientific and engineering problems based on partial differential equations using the finite element method. Simulation of an induction motor in Ansys Maxwell allows you to determine its parameters in various operating modes.

However, the presented mathematical expression does not provide a qualitative assessment of the ongoing processes in the starting mode of an induction motor. To analyse the process of current displacement in the starting mode, a field calculation was carried out using the finite element method of an induction motor with a power of $130 \mathrm{~kW}$, with a number of 4 poles and a supply frequency of $80 \mathrm{~Hz}$. The engine is

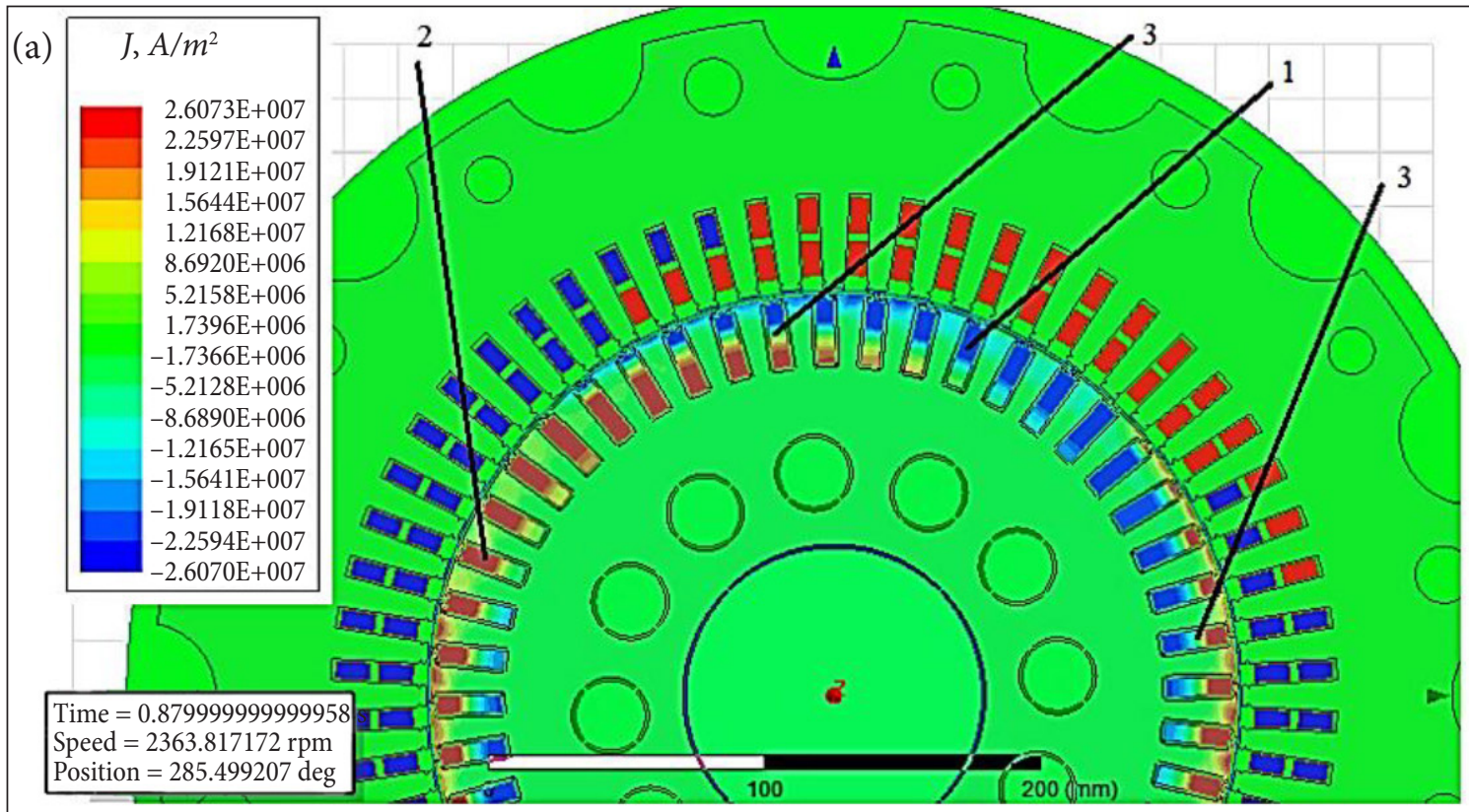

(b)

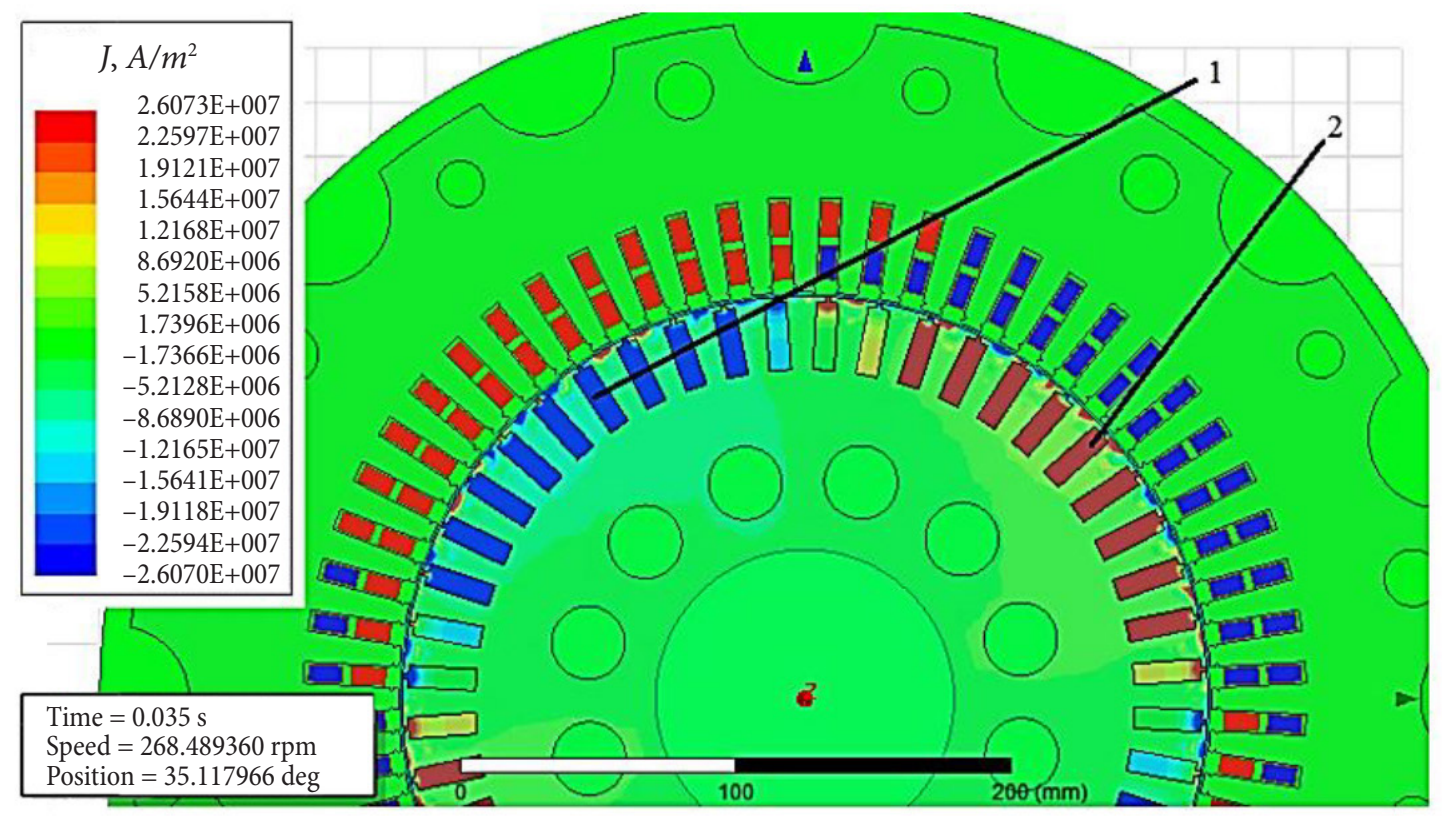

Fig. 5. Determination of current densities in the rods of the rotor winding in starting mode (a) and nominal mode (b) 
a traction drive for an electric train, so its rated frequency differs from the standard value of the industrial frequency.

The results of this calculation are shown in Fig. 5. It is seen that at the time of engine start (0.035 s), an uneven current distribution occurs in the rotor rods. There is a displacement of the current in the radial direction (slots 1 and 2 ). In some grooves of the rotor, current flows simultaneously in two directions (slot 3 ). After completion of the start-up mode $(0.879 \mathrm{~s})$, the currents in the rotor rods are aligned, the current density is distributed over the entire cross-section of the rod. This picture indicates the completion of the transient starting process in the engine. The current values are reduced by 10 times. This can be seen from the value of their density determined in the rods $\left(J, A / m^{2}\right)$.

\section{CONCLUSIONS}

The use of frequency characteristics will improve the accuracy of determining the design parameters of induction motors at the design stage. Taking into account the stator winding resistance, it is possible to accurately determine the characteristics of induction motors in starting conditions, which is important when choosing modern equipment for switching and control for new induction motors.

As practical studies have shown, the proposed method allows the calculation to obtain results that are fairly close to experimental results. This refers to the determination of starting currents and torque on the shaft of an induction motor, which today is a complex and controversial task. The proposed method using powerful computer equipment will solve this problem.

Received 8 December 2019 Accepted 20 March 2020

\section{References}

1. Yegorov A., Yegorova O. Analysis of transient processes in an asynchronous motor as part of a complex load. Multidisciplinary Scientific Edition 'WORLD SCIENCE'. 2017. Vol. 1. No. 10. P. 12-15.
2. Sun X., Shi Zh., Chen L., Zebin Yang Z. Internal model control for a bearingless permanent magnet synchronous motor based on inverse system method. IEEE Transactions on Energy Conversion. 2016. Vol. 31. No. 4. P. 1539-1548.

3. Yang Z., Zhang D., Sun X., Ye X. Adaptive exponential sliding mode control for a bearingless induction motor based on a disturbance observer. IEEE Access. 2018. Vol.6. P. 5425-35434.

4. Larin A., Larina I., Sheina A. Study of saturation influence at the totality of turbogenerators electromagnetic parameters. Scientific Works of Donetsk National Technical University. 2011. Vol. 11. No. 186. P. 235-240.

5. Zhenwei H., Wenxin H., Cencen H., Feifei B. Control strategy of self-bearing dual stator solid rotor axial flux induction motor for flywheel energy storage. Proceedings of the IEEE 21st International Conference on Electrical Machines and Systems (ICEMS), 2018. P. 1513-1517.

6. Finkelshtein V. B., Iegorov A. B. Kharakteristiki chetyrekhfaznogo ventilnogo reaktivnogo dvigatelia pri pitanii ot beskondensatornogo kommutatora. Electrical Engineering and Electromechanics. 2016. Vol. 3. P. 21-25.

7. Iegorov O., Iegorova O., Kundenko M., Milenin A. The influence of the phase angle between the rotor magnetic axis and the stator winding current vector on the synchronous reluctance motor efficiency. Proceedings of the IEEE International Conference on Modern Electrical and Energy Systems (MEES), 2019. P. 62-65.

8. Baghaee H. R., Mirsalim M., Gharehpetian G. B. Power calculation using RBF neural networks to improve power sharing of hierarchical control scheme in multi-DER microgrids. IEEE Journal of Emerging and Selected Topics in Power Electronics. 2016. Vol. 4. No. 4. P. 1217-1225.

9. Lv G., Zhou T., Zeng D. Influence of the ladder-slit secondary on reducing the edge effect and transverse forces in the linear induction motor. IEEE Transactions on Industrial Electronics. 2018. Vol. 65. No. 9. P. 7516-7525.

10. Yu Q., Bilgin B., Emadi A. Loss and efficiency analysis of switched reluctance machines using a new calculation method. IEEE Transactions on Industrial Electronics. 2015. Vol. 62. No. 5. P. 3072-3080. 
11. Komada P., Trunova I., Miroshnyk O., Savchenko O., Shchur T. The incentive scheme for maintaining or improving power supply quality. Przegląd elektrotechniczny. 2019. Vol. 5. P. 79-82.

Oleksiy Iegorov, Olga Iegorova,

Oleksandr Miroshnyk, Oleksandr Savchenko

ASINCHRONINIŲ VARIKLIŲ PALEIDIMO

PEREINAMŲJŲ PROCESŲ VERTINIMO

METODIKOS TIKSLUMO DIDINIMAS

Santrauka

Elektros mašinų matematiniai modeliai, skirti analitiniam pereinamųjų procesų aprašymui, yra labai svarbūs. Dažninès charakteristikos patikslina asinchroninių variklių modelį, tai itin aktualu projektavimo metu. Straipsnyje aprašomas asinchroninio variklio modelis, papildytas aktyviąa statoriaus apvijos varža, kuri leidžia tiksliai įvertinti variklio paleidimo pereinamojo proceso charakteristikas.

Raktažodžiai: asinchroninis variklis, fazinė charakteristika, apvijos varža, variklio paleidimas, slopinimo koeficientas 